\title{
PATTERN OF USE OF GASTROPROTECTIVE AGENTS ALONG WITH THE ANTI - INFLAMMATORY AND ANALGESICS DRUGS
}

\author{
K. B. Sanalkumar ${ }^{1}$, K. T. Shenoy², K. Arun 3 , Hema Ilavarasi K. M⿻4, Venugopalan P.G5, Leena K. $B^{6}$ \\ ${ }^{1}$ Additional Professor, Department of Pharmacology, Government Medical College, Thrissur. \\ 2 Professor and HOD, Department of Gastroentrology, Sree Gokulam Medical College \& Research Foundation, Thiruvananthapuram \\ Executive Director of Population Health \& Research Institute, Thiruvananthapuram. \\ 3 Professor, Department of Orthopaedics, Government Medical College \& Hospital, Thiruvananthapuram. \\ ${ }^{4} J$ unior Resident, Department of Pharmacology, Government Medical College \& Hospital, Thrissur. \\ ${ }^{5}$ Associate Professor, Department of Anaesthesia, Sree Gokulam Medical College \& Research Foundation, Thiruvananthapuram. \\ ${ }^{6}$ Senior Research Scientist, Population Health and Research Institute, Thiruvananthapuram.
}

ABSTRACT
BACKGROUND
Non-Steroidal Anti-Inflammatory Drugs (NSAIDs) are one of the highly prescribed drugs in the world. In addition to their
beneficial effect, they are having adverse reactions, of which, gastrointestinal toxicity is the most common. The reduction in NSAID-
induced GI toxicity is primarily accomplished by prescribing gastro-protective agents that when co-administered with NSAIDs would
protect against mucosal ulceration and the ideal candidates for co-prescription of gastro-protective agents are those considered to
have a high-risk for NSAID induced ulcers.

\section{OBJECTIVES}

To evaluate the pattern of use of gastro-protective agents along with the anti-inflammatory and analgesics agents and to study the adverse effects in those patients receiving the anti-inflammatory agents and analgesics.

\section{METHODOLOGY}

A cross-sectional study done in orthopaedic outpatient departments of tertiary and secondary health centers of Thiruvananthapuram, which include totally 769 patients. The study was conducted from June $1^{\text {st }}$ to September $30^{\text {th }} 2006$, after ethical clearance from the ethical committee, Government Medical College, Thiruvananthapuram.

\section{RESULTS}

Seven hundred and sixty nine patients were studied from three health facilities in Thiruvananthapuram District. Of the 752 cases receiving NSAIDs/analgesics in this sampling frame, Taluk hospital is receiving the highest percentage of co-prescription with gastro-protective agents (96.8\%). In General hospital, 247 cases received NSAIDs/analgesics out of which 95 cases only received gastro-protective agents (38\%), the lowest \% among the three centers. Out of 262 cases in the MCH, 249 cases received NSAIDs/analgesics in which 193 cases received gastro protective agents (77.5\%). In the total sample, 126 patients reported with any one of the adverse effect (16.7\%); 50 cases were from the general hospital (20\%), 20 cases from MCH (8\%) and the remaining 56 cases from Taluk hospital $(21.8 \%)$.

\section{CONCLUSION}

Co-Prescription of Gastro-Protective Agents (GPA) along with NSAIDs/analgesics in our setting ranges from 38\% to96.8\%. The adverse drug reactions reported was $16.7 \%$ among the total sample. The benefit of the co-prescription needs to be assessed on the risk group of NSAID user, long term or short term use of NSAID and the pharmacological group of GPA used for co-prescription.

\section{KEYWORDS}

NSAIDs, Gastro Protective Agents, PPIs.

HOW TO CITE THIS ARTICLE: Sanalkumar KB, Shenoy KT, Arun K, et al. Pattern of use of gastroprotective agents along with the anti-inflammatory and analgesics drugs. J Evolution Med Dent Sci 2016;5(1):50-54, DOI: 10.14260/jemds/2016/12

\section{INTRODUCTION}

Non-Steroidal Anti-Inflammatory Drugs (NSAIDs) are being consumed widely in the world for the treatment of pain, inflammation and fever. ${ }^{1}$ and they are one of the most common cause of Adverse Drug Reactions (ADRs) reported to drug regulatory agencies as well as in many as well as in many clinical and epidemiological studies. ${ }^{2}$

Financial or Other, Competing Interest: None.

Submission 29-11-2015, Peer Review 30-11-2015,

Acceptance 29-12-2015, Published 02-01-2016.

Corresponding Author:

Dr. K. B. Sanalkumar,

Additional Professor,

Department of Pharmacology,

Government Medical College,

Thrissur-680596,

Kerala.

E-mail: Sanaldr2001@yahoo.com

DOI:10.14260/jemds/2016/12
The most common ADRs are gastrointestinal toxicity symptoms such as dyspepsia and bleeding. ${ }^{3,4}$ The complications which account for almost all NSAID-associated GI mortality are bleeding and perforation, and they have increasing prevalence with advancing age. ${ }^{5}$

There have been conflicting data as to the effect of duration of NSAID exposure on the risk of NSAID-related GI events. Some case-control studies have suggested that the risk of NSAID-associated GI complications is highest within the first 30 days of NSAID use. ${ }^{6}$

A potential explanation for this perceived early high-risk period could be that with continued NSAID exposure the gastric mucosa adapts to the injurious effects of NSAIDs, thus becoming more resistant later in the course of continued NSAID exposure (A phenomenon referred to as gastric 
adaptation), because most patients who take NSAIDs long term never experience clinically significant ulceration. ${ }^{7}$

The NSAID users are categorized to low, moderate and high-risk group that further recommends the co-prescription of gastro-protective agents for moderate and high-risk users. The reduction in NSAID-induced GI toxicity is primarily accomplished by prescribing gastro-protective agents that when co-administered with NSAIDs would protect against mucosal ulceration and the ideal candidates for coprescription of GPAs are those considered to have high risk for NSAID-induced ulcers. ${ }^{8}$

A number of studies have evaluated whether an $\mathrm{H}_{2}$ receptor antagonist $\left(\mathrm{H}_{2} \mathrm{RA}\right)$, when co-administered with an NSAID, can prevent NSAID-induced ulcers. ${ }^{8,9}$ Misoprostol, an analogue of prostaglandin E1, has been specifically approved for the prevention of NSAID-induced ulcers in high-risk patients. ${ }^{10}$ Use of Proton Pump Inhibitors (PPIs) for prophylaxis against NSAID ulcers has become an attractive strategy for many clinicians. ${ }^{11} \mathrm{We}$ conducted this study to evaluate whether the co-prescription of gastro-protective agents along with NSAIDs are beneficial to the patients.

\section{METHODOLOGY}

\section{OBJECTIVE}

1. To evaluate the pattern of use of gastro-protective agents along with the anti-inflammatory and analgesics Drugs.

2. To study the adverse effects in those patients receiving the anti-inflammatory agents and analgesics.

\section{MATERIALS AND METHODS}

A cross-sectional study done in orthopedic outpatient departments of tertiary and secondary health centers of Thiruvananthapuram which include totally 769 patients which includes 262 cases from Medical College Hospital, Thiruvananthapuram and 250 cases from District Hospital, Thiruvananthapuram and 257 cases from Taluk Hospital, Chirayinkil and the sample size needed was 246. Sample size was calculated based on proportions of expected NSAID usage as $80 \%$ and with a precision of $5 \%$ and confidence level (1alpha) as $95 \%$ by using the software designed and developed by Biostatistics Resources and training center, Christian Medical College, Vellore.
The study was conducted from June $1^{\text {st }}$ to September $30^{\text {th }}$ 2006, after ethical clearance from the ethical committee, Government Medical College, Thiruvananthapuram.

Data were analysed using descriptive statistics for the study variables.

\section{RESULTS}

\begin{tabular}{|c|c|c|c|c|}
\hline $\begin{array}{c}\text { Name of } \\
\text { Facilities }\end{array}$ & $\begin{array}{c}\text { District } \\
\text { Hospital, } \\
\text { TVM }\end{array}$ & $\begin{array}{c}\text { MCH, } \\
\text { TVM }\end{array}$ & $\begin{array}{c}\text { Taluk } \\
\text { Hospital, } \\
\text { Chirayin } \\
\text { kil }\end{array}$ & Total \\
\hline $\begin{array}{c}\text { Number } \\
\text { of } \\
\text { Patients }\end{array}$ & $\begin{array}{c}250 \\
(32.50 \%)\end{array}$ & $\begin{array}{c}262 \\
(34.08 \%)\end{array}$ & $\begin{array}{c}257 \\
(33.42 \%)\end{array}$ & $\begin{array}{c}769 \\
100 \% \\
)\end{array}$ \\
\hline $\begin{array}{c}\text { Age } \\
\text { Mean } \pm \text { SD }\end{array}$ & $\begin{array}{c}44.01 \pm 13 . \\
08\end{array}$ & $\begin{array}{c}42.55 \pm 14 . \\
09\end{array}$ & $44 \pm 13.06$ & - \\
\hline \multicolumn{5}{|c|}{ Table 1: Characteristics of the Study } \\
\hline \multicolumn{5}{|c|}{ Population by facility } \\
\hline
\end{tabular}

The ages were comparable in three different health care settings.

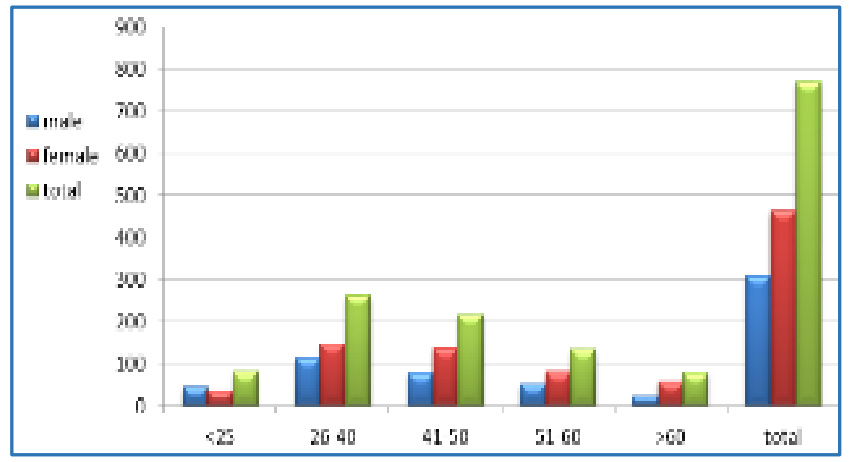

Fig. 1: Age and Sex Distribution

There were 308 males and 461 females; age ranged from 18-85 years among males and 18-89 among females.

\begin{tabular}{|c|c|c|c|c|c|c|c|}
\hline Analgesic & Ranitidine & Famotidine & Omeprazole & Pantoprazole & $\begin{array}{c}\text { Rabepra } \\
\text { zole }\end{array}$ & Antacid & Total \\
\hline Aceclofenac & 50 & 2 & 1 & 57 & 0 & 2 & 112 \\
\hline Diclofenac & 146 & 4 & 7 & 32 & 2 & 3 & 194 \\
\hline Ibuprofen & 121 & 0 & 0 & 1 & 0 & 0 & 122 \\
\hline Paracetamol & 16 & 0 & 0 & 1 & 0 & 0 & 17 \\
\hline Indomethacin & 13 & 2 & 0 & 6 & 1 & 0 & 22 \\
\hline Serratiopeptidase & 2 & 0 & 0 & 2 & 0 & 0 & 4 \\
\hline Mefenamic acid & 0 & 0 & 0 & 0 & 1 & 0 & 1 \\
\hline Etoricoxib & 8 & 0 & 0 & 1 & 0 & 0 & 9 \\
\hline Meloxicam & 0 & 3 & 1 & 1 & 0 & 0 & 5 \\
\hline Piroxicam & 0 & 1 & 0 & 1 & 0 & 0 & 2 \\
\hline Nimesulide & 36 & 0 & 0 & 0 & 0 & 0 & 36 \\
\hline Aspirin & 12 & 0 & 0 & 0 & 0 & 0 & 12 \\
\hline Total & $\mathbf{4 0 4}$ & $\mathbf{1 2}$ & $\mathbf{9}$ & $\mathbf{1 0 2}$ & $\mathbf{4}$ & $\mathbf{5}$ & $\mathbf{5 3 6}$ \\
\hline
\end{tabular}

Ranitidine was the most commonly used Gastro-protective agent, out of 536 cases received GPA, 404 cases were prescribed with ranitidine (75.37\%), second most common GPA was pantoprazole, 102 out of $536(19.02 \%)$. 


\begin{tabular}{|c|c|c|c|c|}
\hline \multirow{2}{*}{ Drug } & \multicolumn{3}{|c|}{ Facility Wise } & \multirow{2}{*}{ Total } \\
\cline { 2 - 4 } & $\begin{array}{c}\text { DISTRICT } \\
\mathbf{N = 2 5 0}\end{array}$ & $\begin{array}{c}\text { MCH } \\
\mathbf{N = 2 6 2}\end{array}$ & $\begin{array}{c}\text { TALUK } \\
\mathbf{N = 2 5 7}\end{array}$ & \\
\hline Ranitidine & 91 & 75 & 238 & 404 \\
\hline Famotidine & 0 & 12 & 0 & 12 \\
\hline Omeprazole & 1 & 6 & 2 & 9 \\
\hline Pantoprazole & 0 & 96 & 6 & 102 \\
\hline Rabeprazole & 0 & 4 & 0 & 4 \\
\hline Antacid & 3 & 0 & 2 & 5 \\
\hline Total & $\mathbf{9 5}$ & $\mathbf{1 9 3}$ & $\mathbf{2 4 8}$ & $\mathbf{5 3 6}$ \\
\hline \multicolumn{5}{|c|}{ Table3: Pattern of Gastro-protective } \\
Agents use by facilities \\
\hline
\end{tabular}

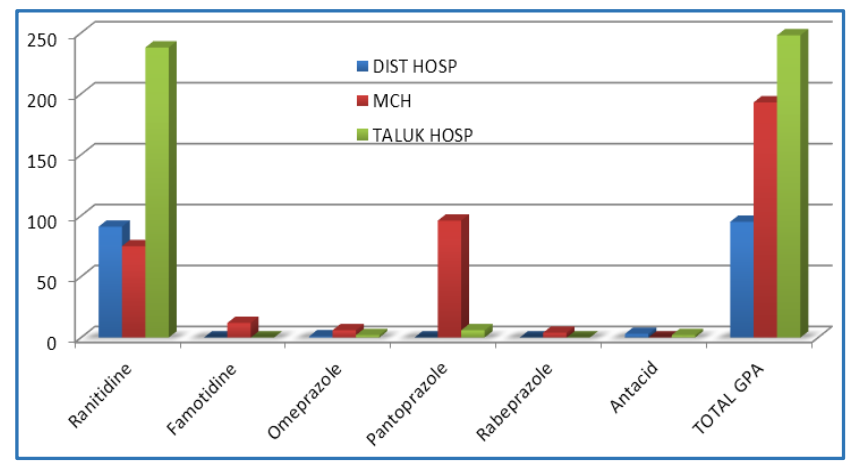

Fig. 2: Pattern of Gastro-protective Agents use by facilities
256 of 257 cases in the Taluk Hospital received NSAIDs/analgesics and among 256 cases 248 cases received gastro protective agents (96.8\%), highest \% of gastro protective use was in Taluk Hospital. 247 of 250 cases in the General Hospital received NSAIDs/analgesics and among the 247 cases 95 cases only received gastro protective agents (38\%). This is the lowest percentage among the three centers. 249 of 262 cases in the MCH received NSAIDs/analgesics and among 249 cases 193 cases received gastro protective agents (77.5\%).

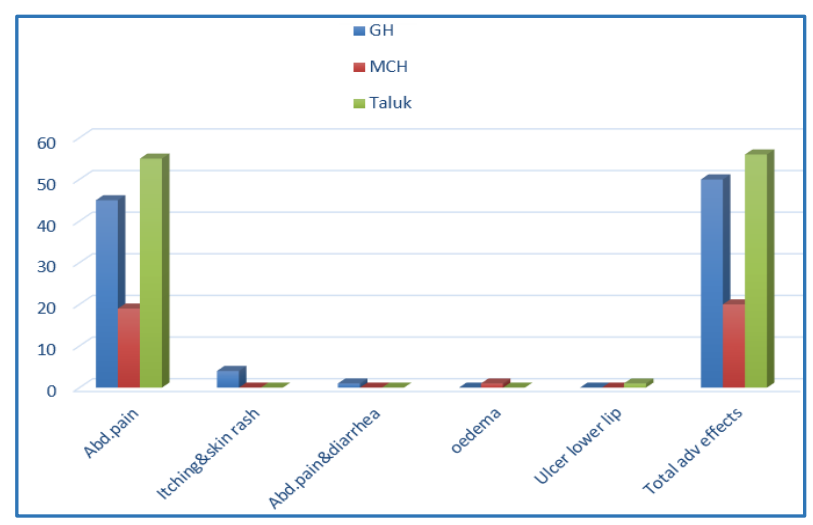

Fig. 3: Pattern of Adverse drug reaction in health care settings

\begin{tabular}{|c|c|c|c|c|c|c|c|}
\hline Drugs & $\begin{array}{l}\text { No } \\
\text { ADR }\end{array}$ & $\begin{array}{c}\text { Abdominal } \\
\text { pain/Heart Burn }\end{array}$ & $\begin{array}{c}\text { Generalised } \\
\text { Oedema }\end{array}$ & $\begin{array}{l}\text { Itching and } \\
\text { Skin rash }\end{array}$ & $\begin{array}{l}\text { Ulcer on } \\
\text { lower lip }\end{array}$ & $\begin{array}{l}\text { Abd. Pain } \\
\text { And } \\
\text { Diarrhoea }\end{array}$ & Total \\
\hline Aceclofenac & 113 & 19 & 0 & 0 & 1 & 0 & 133 \\
\hline Diclofenac & 266 & 47 & 1 & 1 & 0 & 1 & 316 \\
\hline Ibuprofen & 112 & 26 & 0 & 0 & 0 & 0 & 138 \\
\hline Paracetamol & 35 & 6 & 0 & 1 & 0 & 0 & 42 \\
\hline Indomethacin & 26 & 2 & 0 & 1 & 0 & 0 & 29 \\
\hline Serratiopeptidase & 9 & 0 & 0 & 0 & 0 & 0 & 9 \\
\hline Tramadol & 1 & 0 & 0 & 0 & 0 & 0 & 1 \\
\hline Mefenamic acid & 1 & 0 & 0 & 0 & 0 & 0 & 1 \\
\hline Etoricoxib & 12 & 5 & 0 & 0 & 0 & 0 & 17 \\
\hline Meloxicam & 5 & 1 & 0 & 0 & 0 & 0 & 6 \\
\hline Piroxicam & 8 & 2 & 0 & 1 & 0 & 0 & 11 \\
\hline Nimesulide & 28 & 9 & 0 & 0 & 0 & 0 & 37 \\
\hline Aspirin & 10 & 2 & 0 & 0 & 0 & 0 & 12 \\
\hline No Drug & 17 & 0 & 0 & 0 & 0 & 0 & 17 \\
\hline Total & 643 & 119 & 1 & 4 & 1 & 1 & 769 \\
\hline
\end{tabular}

\begin{tabular}{|c|c|c|c|c|}
\hline \multirow[b]{2}{*}{ ADR Reported } & \multicolumn{3}{|c|}{ Facility Wise } & \multirow[b]{2}{*}{$\begin{array}{c}\text { Total } \\
N=769\end{array}$} \\
\hline & $\begin{array}{c}\text { GH } \\
\mathrm{N}=250\end{array}$ & $\begin{array}{c}\text { MCH } \\
\mathrm{N}=262\end{array}$ & $\begin{array}{r}\text { Taluk } \\
\text { N=257 }\end{array}$ & \\
\hline $\begin{array}{l}\text { Both Abdominal } \\
\text { Pain and Heart } \\
\text { Burn }\end{array}$ & 45 & 19 & 55 & 119 \\
\hline $\begin{array}{l}\text { Itching and skin } \\
\text { rash }\end{array}$ & 4 & 0 & 0 & 4 \\
\hline $\begin{array}{c}\text { Abd.Pain and } \\
\text { diarrhoea }\end{array}$ & 1 & 0 & 0 & 1 \\
\hline Oedema & 0 & 1 & 0 & 1 \\
\hline Ulcer Lower Lip & 0 & 0 & 1 & 1 \\
\hline Total & 50 & 20 & 56 & 126 \\
\hline
\end{tabular}

Out of 752 cases receiving NSAIDs from the total sample in all the three health care settings, 126 cases reported with any one of the adverse effect (16.7\%), out of which 50 cases were from the general hospital (20\%), 20 cases were from MCH (8\%)and the remaining 56 cases were from Taluk hospital (21.8\%).

Among the 126 cases, 119 cases with abdominal pain and 4 cases with itching and skin rash, one case with both abdominal pain and diarrhea, one with generalized edema and one with ulcer on lower lip. 


\begin{tabular}{|c|c|c|c|c|}
\hline & GH & MCH & Taluk & Total \\
\cline { 2 - 5 } & $\mathrm{N}=250$ & $\mathrm{~N}=262$ & $\mathrm{~N}=257$ & $\mathrm{~N}=769$ \\
\hline $\begin{array}{c}\text { Total No with } \\
\text { NSAIDs/analgesics }\end{array}$ & 247 & 249 & 256 & 752 \\
\hline $\begin{array}{c}\text { Total No. of } \\
\text { NSAIDs/analgesics } \\
\text { with GPA }\end{array}$ & 95 & 193 & 248 & 536 \\
\hline $\begin{array}{c}\text { \% case with GPA } \\
\text { Total No. ADR }\end{array}$ & 58 & 77.5 & 96.8 & 71 \\
\hline $\begin{array}{c}\text { Total No. of cases } \\
\text { with abd.pain }\end{array}$ & 45 & 19 & 55 & 119 \\
\hline $\begin{array}{c}\text { \% case with } \\
\text { Abd.Pain }\end{array}$ & 18.6 & 7.6 & 21.4 & 15.82 \\
\hline $\begin{array}{c}\text { Table 6: Gastro-protective agents (GPA) used along with } \\
\text { NSAIDs/Analgesics and the pattern of ADR in different } \\
\text { Facilities }\end{array}$
\end{tabular}

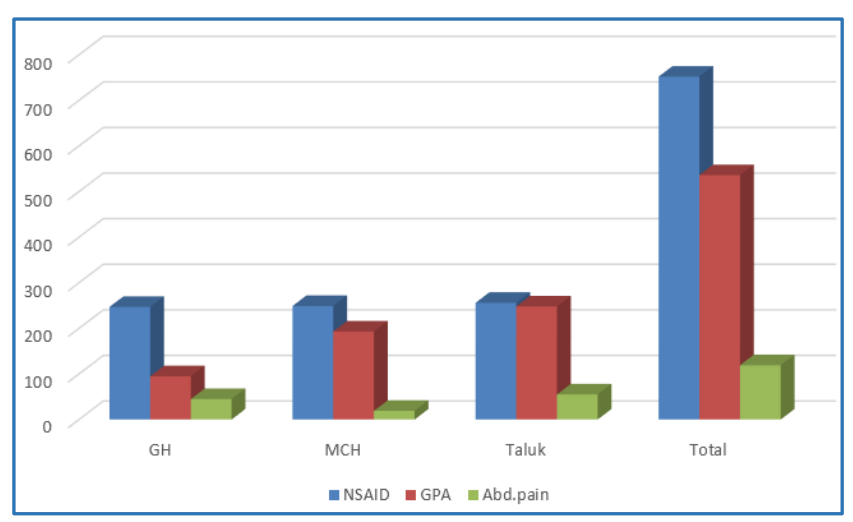

Fig. 4: Gastro-protective agents (GPA) used along with NSAIDs/Analgesics and the pattern of ADR in different Facilities

\section{DISCUSSION}

Of the 769 patients evaluated in three health care facilities, 262 subjects were from the orthopedic outpatients department in the Medical College Thiruvananthapuram. $50.8 \%$ were males and $49.2 \%$ were females. In General Hospital, out of 250 patients, only $33.6 \%$ were males and $66.4 \%$ were females. In Taluk Hospital out of 257 patients, $35.4 \%$ were males and $66.4 \%$ were females. Both in Taluk and General Hospital female patients seeking health care were high.

Similar to our observation, Dale et al. showed that females used more analgesics compared to males. ${ }^{12}$ In total, 308 cases were males and 461 cases were females; age ranged from 18-85 years in males and 18-89 years in females, $1^{\text {st }}$ quartile of age was 34 and second quartile of age was 43 and $3^{\text {rd }}$ quartile was 52 years. In our study, it was seen that most ADRs presented in the age group of 41-50 years. Minimal ADRs were seen below 25 years of age. As age increases the chance for developing ADR also increases. ${ }^{13}$

Mean ages were comparable in the different health care settings. In the taluk hospital, more people were illiterate and just literate compared to medical college and general hospital. Alcoholic abuse were almost same in three different settings.

In the Taluk Hospital, 256 of 257 cases received NSAIDs/analgesics; 248 cases received gastro-protective agents (96.8\%), highest proportion of gastro-protective agent use was in Taluk Hospital. In the General Hospital, 247 of 250 cases received NSAIDs/analgesics and among the 247 cases 95 cases only received gastro-protective agents (38\%). This is the lowest percentage among the three centers. In the MCH, 249 of 262 cases received NSAIDs/analgesics and among 249 cases 193 cases received gastro-protective agents (77.5\%).

Among the GPA co-prescription, Ranitidine was the most commonly used Gastro-protective agent, out of 536 cases received GPA, 404 cases were prescribed with ranitidine (75.37\%), second most common GPA was pantoprazole, 102 out of 536 (19.02\%). Both in Taluk and General Hospital most cases were prescribed with Ranitidine whereas in $\mathrm{MCH}$ Pantoprazole was commonly used. This discrepancy in the usage of GPA is due to the availability of drugs in that particular health center.

Of the 752 case receiving NSAIDs/analgesics in the health settings, 126 cases reported with any one of the adverse effect (16.7\%); 119 cases with abdominal pain and 4 cases with itching and skin rash and one case with both abdominal pain and diarrhea and one with generalized oedema. In the taluk hospital, 56 cases reported adverse reactions, $(21.8 \%)$, highest among the three centers, in which 55 cases presented with abdominal pain and one case with ulcer lower lip.

In the General hospital, 50 cases reported adverse effects (20\%), 45 cases with abdominal pain and 4 cases with itching and skin rash and one case with both abdominal pain and diarrhea. In the $\mathrm{MCH}, 20$ cases reported adverse reactions (8\%), this is the lowest percentage of adverse reaction reported among the three centers. ADR reported are 19 cases with abdominal pain and one case with oedema.

In males, Diclofenac caused $11.8 \%$ ADR, followed by Aceclofenac, which caused $8 \%$ and Ibuprofen with 7.3\%. While in females, Ibuprofen caused $23 \%$ ADR, followed by Aceclofenac with 21.1\% ADR, and Diclofenac caused 19\% ADR.

In Taluk Hospital, even though most patients were prescribed with GPA, the ADR seen was also high, the reason may be here the females received NSAIDs more compared to males and also the commonly used drug was Ibuprofen which has caused ADR more in females. Both in Taluk and General Hospital, the most common GPA prescribed was Ranitidine, but in several study. 7,8 it has been found that $\mathrm{H}_{2}$ blockers are not protective against NSAIDs-induced gastric irritation which also favors the same.

Antacids were used rarely in the taluk and general hospital since they are indicated only for symptomatic relief of pain and are associated with drug interactions which restrict their rational indication for use. Other reason behind this may be as both are secondary health centers the out patients belongs to low risk category NSAID users and they were using on short- term basis.

In MCH, GPA co-prescription is about $77.5 \%$ in which PPIs were most commonly prescribed and reported the lowest percentage of adverse reaction among the three centers. $\mathrm{MCH}$ being a tertiary care Centre the patients belongs to high-risk category and they were using NSAIDs on long-term basis.

Misoprostol, the drug indicated for the prophylaxis of high risk individuals, was not used in any of the health centers. The reasons might be high cost, frequent side effects and the need for multiple daily dosing of Misoprostol.14

Co-prescription of GPAs along with NSAIDs/analgesics was not found to be statistically significant in our study $(\mathrm{P}=0.49)$. Previous literature have shown that $\mathrm{H}_{2}$ blockers are not protective against NSAIDs induced gastric irritation and in 
our study the main gastro-protective agent used was an $\mathrm{H}_{2}$ blocker Ranitidine. This might be a reason for the nonsignificance of gastro-protective agent usage. However, the use of PPIs as gastro-protective agent is necessary for patients on long-term use of NSAIDs and for high-risk category.

\section{CONCLUSION}

Co-Prescription of gastro-protective agents (GPA) along with NSAIDs/analgesics in our setting ranges from $38 \%$ to $96.8 \%$. The adverse drug reactions reported was $16.7 \%$ among the total sample. The benefit of the co-prescription of GPA needs to be assessed on the basis of risk group of NSAID user, long term or short term use of NSAID and the pharmacological group of GPA used for co-prescription.

\section{REFERENCES}

1. Mau Sinha, Lovely Gautam, Prakash Kumar Shukla, Punit Kaur, Sujata Sharma, and Tej P Singh. Current perspectives in NSAID-Induced Gastropathy. Mediators of Inflammation. Hindawi Publishing Corporation, 2013;P.1-11.

2. Gupta M, Malhotra S, et al. Pattern of prescription of nonsteroidal anti-inflammatory drugs in orthopedic outpatient clinic of a North Indian Tertiary Care Hospital, Indian J Pharmacology, 2005;37:P.404-405.

3. Padmaja Udayakumar. Text book of Medical Pharmacology, 2004;1:P. 42-45.

4. Wolfe MM, Lichtenstein DR, Singh G. Gastrointestinal toxicity of non-steroidal anti-inflammatory drugs. N Engl J Med, 1999;340:P.1888-1899.

5. Armstrong CP, Blower AL. Non-steroidal antiinflammatory drugs and life threatening complications of peptic ulceration. Gut, 1987;28:P.527-532.

6. Gabriel SE, Jaakkimainen L, Bombardier C. Risk for serious gastrointestinal complications related to use of non-steroidal anti-inflammatory drugs. Ann Intern Med, 1991;115:787-796.

7. Silverstein FE, Graham DY, Senior JR, et al. Misoprostol reduces serious gastrointestinal complications in patients with rheumatoid arthritis receiving nonsteroidal anti-inflammatory drugs: A randomized, double-blind, placebo-controlled trial. Ann Intern Med, 1995; 123:241-249.
8. Ten Wolde S, Dihjkmans BACJM, Hermans J, et al. Highdose ranitidine for the prevention of recurrent peptic ulcer disease in rheumatoid arthritis patients taking NSAIDs. Aliment Pharmacol Ther, 1996;10:347-351.

9. Robinson MG, Griffin JW, Bowers J, et al. Effect of ranitidine gastroduodenal mucosal damage induced by non-steroidal anti-inflammatory drugs. Dig Dis Sci 1989;34:424-428.

10. Manohar VS, Vinay M, Jayasree T, Kishan PV, Ubedulla S, Rohit Dixit. Prescribing pattern of gastroprotective agents with non-steroidal anti-inflammatory drugs. Journal of Pharmacology and Pharmacotherapeutics, 2013 January-March;4(1):P.59-60.

11. Yeomans ND, Tullasay Z, Juhasz L. A comparison of omeprazole with ranitidine for ulcers associated with non-steroidal anti-inflammatory drugs. N Engl J Med, 1998;338:719-726.

12. Dale O, Borchgrevink PC, Fredheim OMS, Mahic M, Romundstad P, Skurtveit S. Prevalence of use of nonprescription analgesics in the Norwegian HUNT3 population: Impact of gender, age, exercise and prescription of opioids. BMC Public Health. 2015;15:461.

13. Chan FK, Graham DY. Review article: prevention of nonsteroidal anti-inflammatory drug gastrointestinal complications--review and recommendations based on risk assessment. Alimentary pharmacology \& therapeutics, 2004 April;19(10):P.1051-1061.

14. Raghavendra B, Narendranath Sanji, Ullal SD, Kamath R, PaiMrsm, Kamath $\mathrm{S}$, et al. Trends in prescribing gastroprotective agents with non-steroidal antiinflammatory drugs in an orthopaedic outpatient unit of a Tertiary Care Hospital. Journal of Clinical and Diagnostic Research, 2009 June;3:P.1553-1556. 